\title{
Mathematics as a Gatekeeper to Engineering: Preliminary Findings from the
} Interview Data

Ms. DeLean Tolbert, Purdue University, West Lafayette

Dr. Monica E Cardella, Purdue University, West Lafayette 


\section{Mathematics as a Gatekeeper to Engineering: Preliminary Findings from the Interview Data}

Abstract

Research suggests that students' experience may support or hinder future success in engineering. Students' experiences with engineering may shape their perception of engineering curriculum at the college level. It may also cause cognitive and learning dissonance, when the ways that a student engaged with precollege engineering activities do not align with the student's experiences in the college engineering classroom. At a large Midwestern university with a unique first-year engineering program, first-year engineering and senior mathematics, engineering, and senior students in a design discipline were invited to participate in an open ended design task. After completing the task, they were interviewed about how they solved the study design task as well as about their perceptions of their mathematical and design abilities. Finally, the students provided insight into their previous experiences with engineering.

This paper will present findings and discussion based upon the students' responses in the follow-up interview. Some emergent themes in the student's responses are: 1) precollege engineering experiences are structurally different than college engineering experiences, 2) students fail to recognize the diverse types of mathematical knowledge they are applying to solve the design task and 3)precollege engineering is more hands-on than college engineering coursework. We anticipate that this work will give instructors insight in to the perceptions and experiences that students have when they enter the college engineering classroom as freshmen and how those ideas may change over time as they work towards completing their degree. This work may also contribute to on-going discussions about how students understand the relationship between engineering, design and mathematical thinking as they are solving everyday engineering problems.

\section{Introduction}

Problems faced by engineers in the profession are considered wicked, complex and illstructured ${ }^{[1]}$. The solutions to these problems are not developed from linear design and mathematical thinking processes. Rather, by addressing these complex problems using the problems solving skills learned in engineering degree programs along with mathematical and design thinking skills, engineers are able to meet and address these problems head on [2]. Yet, engineering education, the vehicle which prepares future practitioners, is often criticized for not preparing students mathematically with the tools and ways of thinking which these problems mandate.

For example, class assignments might be more well- structured as opposed to the more ill-structured problems faced by engineers in the real world. Even before entering college students also have differing experiences with ill-structured problems. Precollege engineering experiences typically do not mirror those experienced by students once they enter college engineering settings. Precollege engineering experiences offer great diversity of content, depth of knowledge, use of the engineering design process and access to -or the development of- design and mathematical thinking ${ }^{[3]}$. For example, a student may have design and problems solving 
experience in First Robotics, which resembles a more ill-structured task ${ }^{[4,5]}$. On the other hand, a student may have a more structured engineering experience, which has a sole focus on direct application of a concept or recently learned knowledge. However, precollege students and transitioning students to college engineering programs often perceive that engineering experiences are "hands-on" due to the ways that they experience precollege engineering learning.

The hands-on nature of precollege experiences could be due to many factors including the goals of exposing and exciting students, the availability of resources, the nature of the course within which the experience takes place, or the knowledge of the facilitator. Students may not be taught design processes rather, they employ problem solving methods more common in mathematics and science fields to solve engineering problems ${ }^{[6]}$. Typically transferability from different fields is desirable. However, in these cases students might actually be transferring skills which counter the thinking needed to address the increasingly more challenging and more illstructured problems of the future. For example, in mathematics education, students are often taught to follow a linear, methodical process to reach the one best solution ${ }^{[7]}$. However, in engineering design, there is not one way to the best solution. Instead there are multiple solution pathways and many solutions -even though one solution might be a more efficient or economical. Engineering students should be able to employ a design process that allows for idea exploration and selection through both divergent and convergent thinking ${ }^{[8-10]}$. With respect to science knowledge applied to engineering problems, students may be applying the scientific method may also limit a students' idea exploration and their convergent and divergent thinking.

Mathematical thinking is also a key skill needed to solve engineering problems. Yet, when students are given tasks to complete they seem to- at times- have a limited understanding of how to develop appropriate mathematical models to help them solve the problems[11]. Mathematical modeling is one of the key mathematical thinking skills. It is the ability to create mathematical representations of the problem at hand. In fact mathematical modeling tasks are often thought to be the best mechanisms by which students can develop confidence with solving ill-structured problems $^{[2]}$.

This research will contribute to the body of knowledge around how students use mathematical thinking to solve engineering problems. After independently completing a 3 hour design task students were invited to reflect on their beliefs, attitudes and perception of mathematical and design thinking through a semi-structured interview. In this paper, our intent is to explore their responses and understand how students perceive their abilities and the enabling and hindering experiences that led them to perceive themselves in that manner. Finally, we compare the students' precollege and college engineering experiences in order to understand the impact of these different experiences on how they approach engineering design problems.

\section{Research Questions}

Our investigation into the diverse ways that students use mathematical and design skills to solve problems led us to develop the following research questions. This paper will specifically provide evidence towards the investigation of research question three.

(1) How do students respond to open-ended, ambiguous design tasks? 
(2) How do mathematical thinking activities impact design thinking activities?

(3) How do students' thinking processes differ based on mathematics, design and engineering backgrounds?

\section{Study Design}

Students are recruited to spend 3 hours designing a playground for a fictitious neighborhood. Students are asked to "think aloud" as they work in isolation solving this open-ended and ambiguous task. Verbal protocol analysis and video analysis technique provide a research approach which allows the research team to uncover invisible thought processes. The thought processes are then analyzed using a coding scheme informed by: (1) Cardella's modified version of Schoenfeld's framework for mathematical thinking ${ }^{[6,12]}$, (2) a framework for design thinking which is informed by previous playground design task studies and (3) emergent themes from the dataset.

Video and audio data of the think-aloud and follow-up interview was recorded for analysis and for use in future education initiatives. Artifacts for this study include: audio and video data, drawings, sketches, researcher field notes, internet browsing history, and screen capture software video and background information on the students mathematical and design experiences, which was collected prior to the start of the design session.

\section{Participants}

The research team is currently recruiting 30 first-year engineering students, 30 seniors completing an engineering degree, 15 seniors completing a degree focused in design (i.e. industrial) and 15 students completing a degree in mathematics. This paper will focus on the results from 29 first-year engineers and seniors in engineering.

\section{Research Setting}

The semi-structured interview protocol consisted of 18 questions which were focused around four themes: the design task, attitudes and beliefs about mathematical thinking, attitudes and beliefs about design thinking and attitudes and beliefs about engineering thinking. The interview was facilitated after each students' participation in the playground for the purposes of this study, this results discussed will include questions directly related to students discussions of their experiences with engineering design and problem solving before and during college and their beliefs and attitude about mathematical thinking.

\section{Data Analysis}

For this preliminary investigation, the transcripts from the interview data were not used as the primary source of coding. Rather the memos for each students respective interview were used in order to get an initial understanding of the evidence the data might provide. The memos were coded using an emergent coding framework along with the beliefs and affects and problem solving aspects of the modified Schoenfeld mathematical thinking framework.

Results 
Design Thinking: Enabling Experiences

After reading through the memos for the interviews and coding each respectively, the code "enabling experiences" emerged from the data. Within that code there are five themes:

- Ordinary life experiences

- Tinkering and building on own time

- College courses and projects
- Childhood

- Precollege courses

More of the students contributed their engineering courses to enabling them to solve the playground design task and they also believed that the courses helped them to solve open-ended problems. Students typically recalled introductory engineering courses (both honors and traditional) but some students also acknowledge the ways that mathematics courses contributed to their ability to solve this type of problem. A handful of students shared that their extracurricular activities (i.e. work, student organizations, volunteering) helped them to get the practical experience they needed to complete the playground design task. With respect to the emergent codes: Tinkering, building on ones own time might be merged with the code "Enabling Experiences" in the future as the dataset grows.

Students also shared that life experiences enabled them to solve the playground design task. For example, childhood experiences seemed to relate to seeing their parents build play-sets or other items around the house. While most of the students, who shared this experience, did not state that they had an active role in building, they do recount that this helped them understand the process and the materials necessary to complete it.

Finally, students also shared that their algebra and geometry classes from middle and high school helped them understand how to build some of the pieces of equipment in their design. Beyond knowledge of how materials can be put together, some students also commented that the math and science (i.e. physics) classes had design and engineering type problems where they could practice applying knowledge and solving problems. But the students said, they were not taught the engineering design process and the problems that they were typically given were not typically open-ended. They generally resembled linear mathematics problems.

Students were also asked to compare their college design experiences/knowledge to that before college:

"How do they [design skills] compare to your design skills learned in college?"

In the question which immediately preceded the above question in the interview protocol, students reflected on classes or experiences in which they learned design skills. The research team anticipated that most students will reflect on college experiences. For those students, who were first-year engineering students, we anticipated that those students will reflect on precollege experiences. This follow-up question allowed the facilitator to probe the students for comparisons between the knowledge they state they learned in their college experiences and those learned in precollege experiences. At the first iteration of coding, the coder grouped the 
responses by question and then coded the response, using an emergent framework. The codes "Differential DES Experience" emerged from the data along with the following themes:

- No experience

- High school (HS)

○ HS Problems have more constraints

- HS Less developed tasks

- Scientific method not Engineering Design Process

- College same as HS formal classroom experience
- College

○ College open-ended

○ College real world application

- College more planning and mathematical modeling (Engineering Design Process focused)

- Similar to out of school time (OOST) HS activities

In general students with precollege design experiences, felt that they were prescribed and that there was not a lot of room for exploration. Very few students explicitly stated that they had experience with open-ended design problems in their formal precollege curriculum. Students, who had experiences with open-ended tasks with room for exploration, typically attributed learning those skills to informal learning opportunities. There was a small group of students, who felt that the experiences were the same and that there were no distinct differences between the two experiences.

When reflecting on the different ways that they approached problem solving in classes and in college, students often stated that in college there is a preference and focus on following the engineering design process. Some students focused on specific aspects of the process such as modeling and planning. These are practices that they did not often engage in during their engineering and design experiences. Two students explicitly stated that in high school, they used the scientific method rather than the engineering design process. Since they did not use the engineering design process and since exploration was not a component of their projects, students acknowledge that they just followed the instructions provided by their teachers to complete the project.

Mathematical Thinking: Attitudes \& Enabling Experiences

Students were asked to define mathematical thinking. From their definitions, the following themes emerged:

- Knowing when to apply concepts

- Decision making

- Exact (precise)
- Analyze (modeling)

- Problem solving

- Process

- Scaling

The students typically referred to mathematical thinking as using and interpreting numbers to solve problems. Many students thought of mathematics as a methodical, logical process. With respect to the theme "Process", students thought it was one that was linear and had one best solution. Some students referred to mathematical thinking as a route to a correct answer. The 
"Analyze" theme emerged as students discussed "using numbers to analyze a solution", "the results and constraints are based on physically numbers where math is the only way to solve the problem", "understanding something with a quantifiable value." To some extent, students understanding of using mathematical thinking for analysis represents mathematical modeling. But only a few students made that connection explicitly. For example, participant 18 defined mathematical thinking as using "numbers and skills in order to find an unknown about a reality."

What did they believe about their mathematical abilities and experiences?

Students more easily recognize mathematics practices and problem solving strategies. They less often identify or make connections between their beliefs about their ability, their use of cognitive and physical resources and mathematical thinking. With respect to beliefs students where asked the following questions related to their perception of their mathematical ability. Figure 1 depicts the average rating for mathematic and design ability for the different groups in the sample, to date. The students were asked:

Generally, describe how you use mathematics skills to solve open-ended problems? Where do you think you learned those skills?

On a scale from $0-10$, (where $0=$ not confident at all and $10=$ extremely confident), how confident are you in your mathematics ability? Describe the experiences that led you to rate yourself in this way.

What do you think the role of Mathematics is in Engineering?

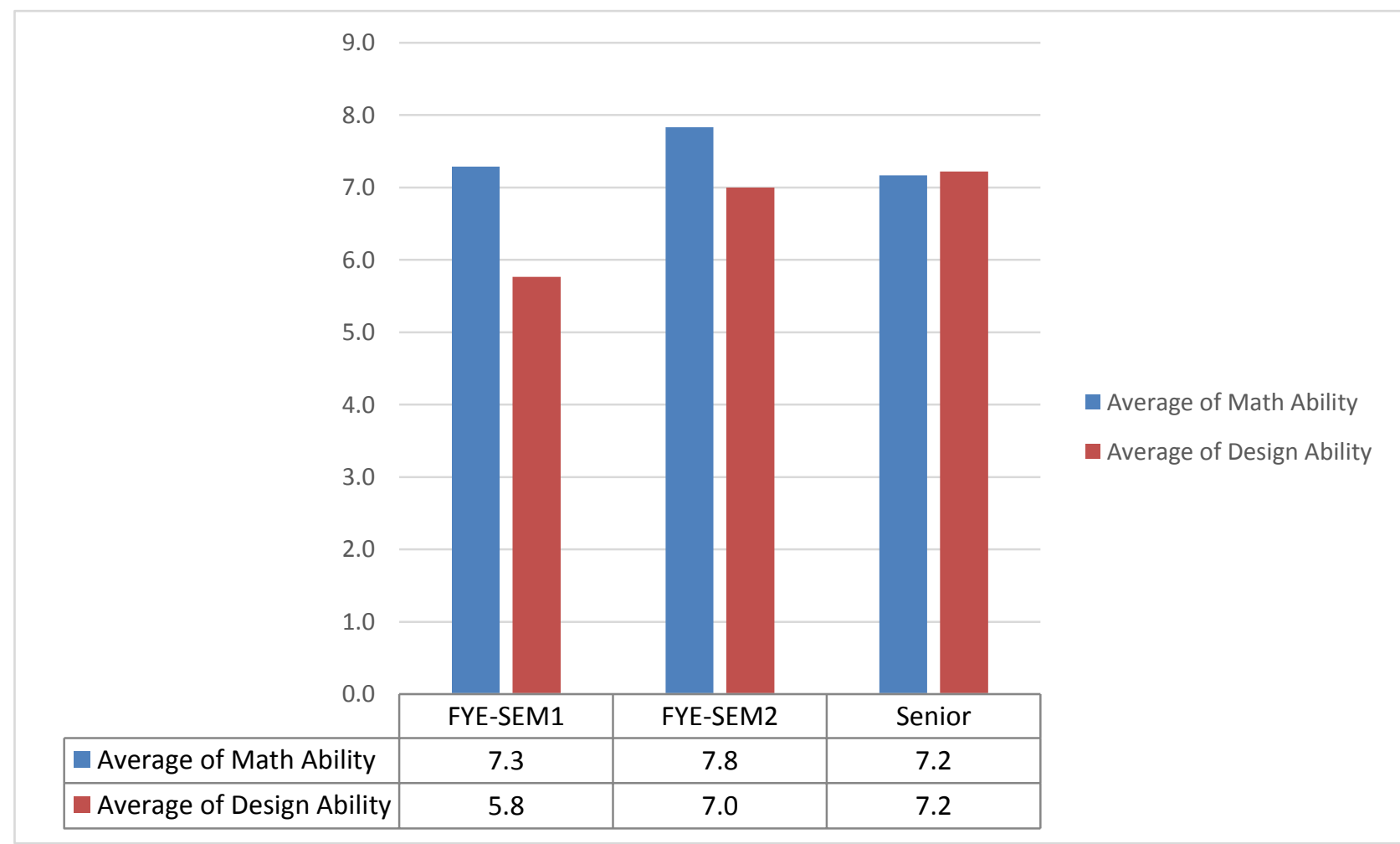

What do

Figure 1: Average rating for mathematics and design ability

design and 
mathematics experiences look like for these students?

Students were asked to reflect and comment on where they think they learned mathematical thinking and design thinking skills. For mathematical thinking the following themes emerged. See Figure 2. The design thinking experiences are displayed in figure 3. Students typically believed that high school design and mathematics experiences are more hands-on. Students learned the skills needed to solve open-ended problems from: family, design courses (in high school), elementary and middle school classes, high school mathematics and science courses, high school out of school time, work experience and ordinary life experiences.

\begin{tabular}{|c|c|}
\hline $\begin{array}{l}\text { Family } \\
\text { Design courses (in high } \\
\text { school), } \\
\text { - Introduction to } \\
\text { mathematical } \\
\text { modeling } \\
\text { Elementary and Middle } \\
\text { School classes, } \\
\text { - How to figure out } \\
\quad \text { costs } \\
\text { High school mathematics and } \\
\text { science courses } \\
\text { - Learning how to study } \\
\quad \text { for exams } \\
\text { - How things work (HW } \\
\text { helps understand that) } \\
\text { - Plug and chug } \\
\text { Dimensional analysis } \\
\text { in Chemistry } \\
\text { High school out of school time } \\
\text { Science Olympiad }\end{array}$ & $\begin{array}{l}\text { Work experience and } \\
\text { ordinary life experiences } \\
\text { - } \\
\text { Everyday decision } \\
\text { making } \\
\text { "on the job- Its a lot } \\
\text { like shopping. You } \\
\text { look for a price that } \\
\text { fulfills certain } \\
\text { requirements within a } \\
\text { certain costs." } \\
\text { College Classroom } \\
\text { - } \\
\text { Described given } \\
\text { specific assignments } \\
\text { and no creativity } \\
\text { Described as "figuring } \\
\text { out how to set up } \\
\text { equations to model the } \\
\text { problem to see } \\
\text { progress" } \\
\text { Learned how to make } \\
\text { assumptions and } \\
\text { simplify the } \\
\text { mathematics } \\
\text { Matlab GUI }\end{array}$ \\
\hline
\end{tabular}

Figure 2: Mathematical Thinking Experiences

\begin{tabular}{|c|c|c|}
\hline $\begin{array}{l}\text { Family } \\
\text { - } \quad \text { Building a bunk bed with } \\
\text { mom } \\
\text { College OOST } \\
\text { - Patent Work } \\
\text { - Summer internship } \\
\quad \text { i.e. Designed a } \\
\quad \text { website }\end{array}$ & $\begin{array}{l}\text { College Design Course } \\
\text { - Sophomore and Senior } \\
\text { Design } \\
\text { - Computer Graphics courses } \\
\text { - User centered design } \\
\text { courses } \\
\text { - Interesting project } \\
\text { - Labs } \\
\text { - EPICS }\end{array}$ & 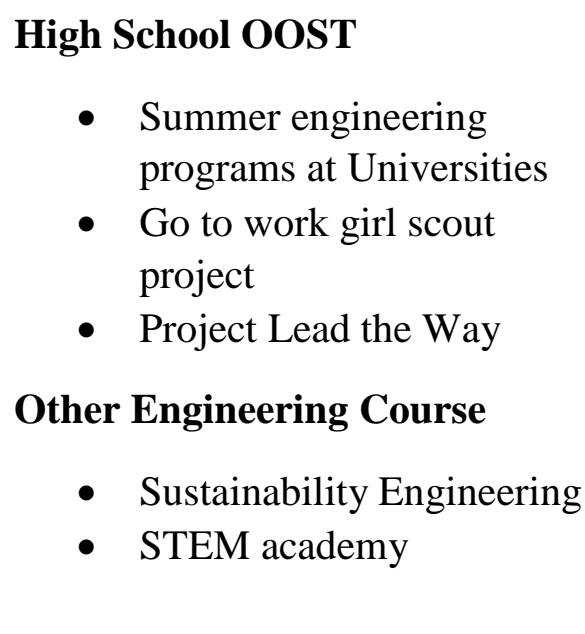 \\
\hline
\end{tabular}




\section{Discussion}

From the interview data, it seems that mathematics learning takes place in pre-college mathematics courses and design thinking skills are learned in college engineering courses. Students reported that mathematics skills were most often learned in classrooms. Students also said that they had been students of mathematics for 15+ years, whereas they are just learning design skills when the get to college. This might explain why students typically rated their design ability lower than their mathematics ability.

First-year engineering students in their first semester of engineering often commented that they had not had the experiences which would help them develop design skills. The average for the first-year engineering student's design ability increased by the second semester, which could mean that they had gained the experience needed to increase their confidence in design.

Students also reported that they learned mathematics and design skills in out of school settings, which range from structured engineering camps, to tinkering around the house and in the community. Another theme from the data is that the mathematics problems are rigidly structured in high school yet the design projects (when they experienced them) were creative and fun. They often found that the engineering projects may have been interesting but were also rigid to some extent and lacked creativity. Students had mixed thoughts on the mathematics course, where some students explicitly expressed their dissatisfaction with the content and the method by which the class was taught.

\section{References}

[1] Jonassen, D., J. Strobel, and C.B. Lee," Everyday problem solving in engineering: Lessons for engineering educators", J. Eng. Educ. Vol. 95, No. 2, 2006, pp. 139-151.

[2] Wedelin, D., T. Adawi, T. Jahan, and S. Andersson," Investigating and developing engineering students' mathematical modelling and problem- solving skills", European Journal of Engineering Education, 2015, pp. 1-16.

[3] Salzman, N., and M. Ohland, "Precollege Engineering Participation Among First-Year Engineering Students", Fifth Annual First Year Engineering Experience Conference (FYEE), Pittsburgh, PA., 2013.

[4] Cardella, M., M. Wolsky, C. Andrews Paulsen, and T. Jones, "Informal Pathways to Engineering: Preliminary Findings", American Society of Engineering Education Annual Conference \& Exposition, Indianapolis,IN, 2014.

[5] Paulsen, C., Wolsky, M., Cardella, M., Jones, T., "Informal Pathways to Engineering: Interim Findings From a Longitudinal Study" Proceedings of the 2015 ASEE Annual Conference and Exposition, Seattle, WA. 
[6] Cardella, M., and C. Atman, "ENGINEERING STUDENTS MATHEMATICAL THINKING: IN THE WILD AND WITH A LAB-BASED TASK", 2007.

[7] Cardella, M., and C. Atman, "Engineering students' mathematical thinking in the wild and with a lab-based task", ASEE Annual Conference \& Exposition 2007.

[8] Dorst, K., and N. Cross," Creativity in the design process: co-evolution of problem-solution", Design Studies Vol. 22, No. 5, 2001, pp. 425-437.

[9] Bailey, R.," Comparative Study of Undergraduate and Practicing Engineer Knowledge of the Roles of Problem Definition and Idea Generation in Design", International Journal of Engineering Education Vol. 24, No. 2, 2008, pp. 226-233.

[10] Dym C. L., Agogino A. M., Eris O., D.D. Frey, and L. Leifer," Engineering design thinking, teaching, and learning", Journal of Engineering Education Vol. 94, No. 1, 2005, pp. 103-120.

[11] Mentzer, N., T. Huffman, and H. Thayer," High school student modeling in the engineering design process", Int J Technol Des Educ Vol. 24, No. 3, 2014, pp. 293-316.

[12] Schoenfeld, A.H., Mathematical thinking and problem solving, Hillsdale, N.J.: Hillsdale, N.J. : L. Erlbaum Associates, 1994. 